\title{
Management of pain in newborn circumcision: a systematic review
}

\author{
Serena Rossi ${ }^{1}$ (D) $\cdot$ Giuseppe Buonocore ${ }^{1} \cdot$ Carlo Valerio Bellieni $^{1}$
}

Received: 27 March 2020 / Revised: 21 July 2020 / Accepted: 27 July 2020 / Published online: 3 August 2020

(C) The Author(s) 2020

\begin{abstract}
Male circumcision (MC) is one of the most common surgical procedures performed on neonates. In the last decades, there have been consistent advances in the understanding of pain mechanisms in newborns, and analgesia has become a fundamental part of neonatal care. MC is still often performed with inappropriate analgesic methods, and there is still great variability among the various centers about surgical and anesthethic techniques to do it. The purpose of this review is to summarize the findings in the literature about pain management and analgesia during newborn MC. We performed a systematic review of neonatal MC studies published in the last 20 years. The most effective technique appeared to be the combination of pharmacological and nonpharmacological methods of analgesia.

Conclusion: Combining local anesthesia with non-pharmacological analgesic strategies appears to be effective preventing procedural pain during MC. However, a standardized protocol for analgesia during MC is yet to be determined. Sensorial saturation appeared to help when used in conjunction with the local anesthesia techniques.
\end{abstract}

What is Known:

- Male circumcision is a painful procedure and it is frequently performed with inappropriate analgesic methods.

- A gold standard practice in analgesia during male circumcision is still lacking and there is a great variability in the modus operandi between centers.

What is New:

- The combination of RB + EMLA + sucrose appears to be an analgesic strategy superior to other approaches.

- We advocate for the integration of sensorial saturation during male circumcision in order to improve the efficacy of current analgesic practices.

Keywords Male circumcision $\cdot$ Newborn pain $\cdot$ Analgesia $\cdot$ Sensorial saturation

Abbreviations

DPNB Dorsal penile nerve block

EMLA Eutectic mixture of local anesthetics

FLACC Face, Legs, Activity, Cry, Consolability scale

LMX4 Lidocaine $4 \%$ cream

MBPS Modified Behavioral Pain Scale

Communicated by Gregorio Paolo Milani

Serena Rossi

serestar90@gmail.com

Giuseppe Buonocore

Giuseppe.buonocore@unisi.it

Carlo Valerio Bellieni

cvbellieni@gmail.com

1 Department of Molecular and Developmental Medicine, University of Siena, Siena, Italy
MC Male circumcision

NFCS Neonatal Facial Coding System

NIPS Neonatal Infant Pain Scale

NNS Non-nutritive sucking

N-PASS Neonatal Pain, Agitation, and Sedation Scale

PIPP Premature infant pain profile

RB Ring block

SS Sensorial saturation

\section{Introduction}

Male circumcision (MC) is one of the oldest and most common surgical procedures in the world. It consists of the shaft skin and inner foreskin surgical removal to uncover the glans. The global prevalence of MC is estimated to be 38-39\% [1]. Given the high rates of circumcision among Muslim and Jewish males, the prevalence of this procedure in the Middle 
East and North Africa reaches over 95\%. In the USA, the prevalence of MC is $91 \%$ in White males, $76 \%$ in Black males, and $44 \%$ in Hispanic males [2]. In other Englishspeaking countries, the prevalence of MC is about $20-30 \%$. In Asian and European countries, the prevalence ranges broadly and this is mainly dependent on the predominant religious beliefs [1]. MC can be performed at any age; it is most commonly performed in neonates, followed by infants and children with important differences in complication rates and related costs $[3,4]$.

Neonatal MC is a simple procedure, healing within 1 week, and when performed in a hospital setting by trained physicians, it has a low rate of adverse events [5]. The reasons for $\mathrm{MC}$ vary but most newborns are circumcised for religious or cultural reasons. There is considerable evidence of the health benefits connected to newborn male circumcision in preventing infectious and non-infectious diseases (i.e., prevention of urinary tract infections, acquisition of HIV, balanitis, paraphimosis, candidiasis, transmission of some sexually transmitted infections, and genital cancer) [5-7]. By contrast, some are less likely to endorse this procedure, and a debate is still ongoing in the medical community whether to recommend neonatal circumcision.

Three surgical devices are commonly used to perform MC: the Gomco clamp, the Plastibell device, and the Mogen clamp (Table 1).

MC performed without anesthesia is likely to be associated with intraoperative and post-operative pain. Therefore, MC should always be performed using anesthesia and postoperative analgesia $[5,8]$. The relief of pain during medical procedures is a crucial goal for healthcare providers, and strong evidence shows that newborns can experience pain and that neuronal pathways are affected by painful stimuli as well as the future pain threshold $[9,10]$. For the risk of neurological damage secondary to the use of general anesthetics,

Table 1 Surgical procedures for male circumcision

\begin{tabular}{ll}
\hline Procedure & Description \\
\hline Gomco clamp & $\begin{array}{c}\text { The device is placed over the glans; the foreskin is } \\
\text { pulled over the bell. Gomco clamp is tightened } \\
\text { and left in place a few minutes to allow for } \\
\text { hemostasis. The foreskin is then cut with } \\
\text { a scalpel [5]. }\end{array}$ \\
It is a device with a slit-like space of 3 mm between \\
two blades. The clamp is placed over the glans and \\
the prepuce is positioned into the slit The blades \\
are locked together, crushing the skin and creating \\
hemostasis. The skin is excised from above the \\
clamp [5].
\end{tabular}

general anesthesia for $\mathrm{MC}$ in newborns should be avoided [11]. The use of local anesthesia for MC has proven to be a safe and effective way to prevent procedural pain both in neonates and in older children $[5,12-15]$.

For many years, physicians have tried to search for analgesic methods to perform MC safely but a gold standard for this practice has not yet been found. The aim of the present study is to systematically review the studies on MC pain management published during the past two decades.

\section{Methods}

We included in our search the original studies, published in the last two decades, comparing the effects of different types of anesthesia/analgesia for neonatal MC or the effects of different surgical techniques for MC on pain levels. We included only studies in which pain level was assessed using specific pain scales or physiologic and behavioral responses to pain. We considered only the studies in which MC was performed during the neonatal period. Only studies written in English were included in the analysis. Reviews, meta-analyses, commentaries, and quality improvement projects were excluded. We retrieved papers from PubMed, MEDLINE, and Cochrane databases using the following combining keywords and MeSH terms: pain, anesthesia, analgesia, newborn, and male circumcision. We consensually decided to use the aforementioned keywords altogether, aiming to increase the possibility of retrieving wellmatched studies. Additional sources used to identify studies included the reference lists of relevant articles and Google Scholar. The final literature search was performed in January 2020 initially with the scanning of titles and abstracts for inclusion and then with the assessment of full-text articles performed by two authors independently (CVB and SR) in order to reduce the possibility of rejecting relevant reports. The study selection process is displayed using the PRISMA flow diagram [16] (Fig. 1). Data were extracted by one author (SR) using a data extraction form, which was independently checked by a second researcher (CVB). Data extracted included the year of publication, the study type, the sample size, the analgesic methods applied, the pain scale used, the surgical technique utilized, and the main results of each study. The data collected were summarized descriptively.

\section{Results}

Forty-seven papers published from the year 2000 were retrieved after initial database search using the aforementioned combined keywords. Forty-five were screened after duplicate removal. Sixteen of them were excluded after the initial scanning of titles and abstract, and eight were excluded after fulltext analysis because they did not fulfill our inclusion criteria. 
Fig. 1 PRISMA 2009 flow diagram

\section{P्याISMA PRISMA 2009 Flow Diagram}

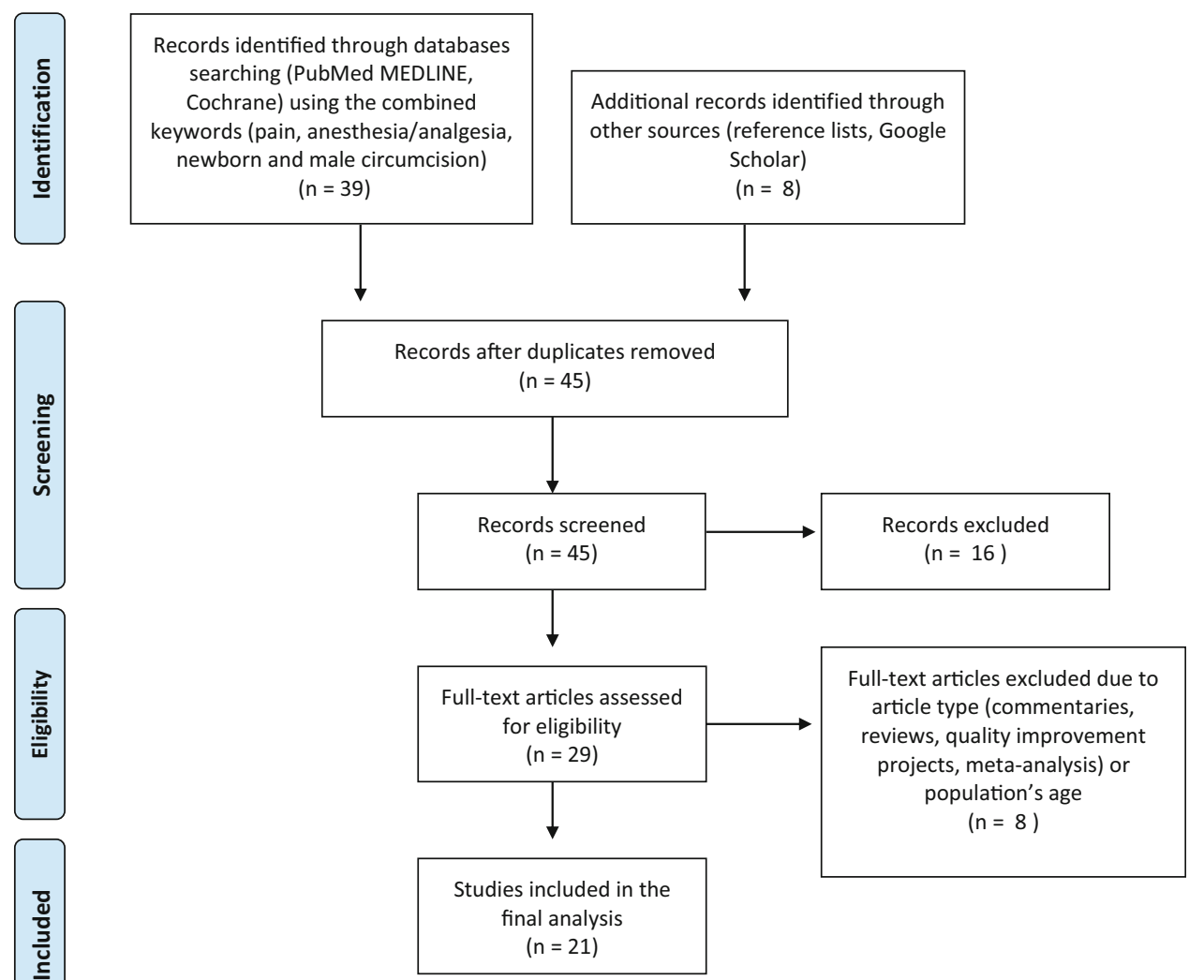

Twenty-one studies met the inclusion criteria and were included in the analysis.

Seventeen articles compared the effect of different analgesic methods in newborns' MC [17-33] while 4 articles compared the effects of different surgical techniques on pain levels [35-38]. Thirteen studies enrolled more than 20 patients for each study group [17, 18, 20, 21, 23, 24, 27-33].

Table 2 displays, in chronological order, a summary of the key features and findings of each of the articles that met the inclusion criteria. Table 3 shows the articles comparing different surgical techniques.

The main pharmacological methods used in the retrieved trials were as follows: EMLA cream which is an eutectic mixture of local anesthetics, with $2.5 \%$ lidocaine and $2.5 \%$ prilocaine producing dermal analgesia when applied as a topical cream on the skin 60-90 minutes before the procedure [5, 22, 26, 31, 32]; dorsal penile nerve block (DPNB) which involves regional anesthesia often obtained with $0.4 \mathrm{ml}$ of $1 \%$ lidocaine or with bupivacaine injected at the base of the penis at the 10:00 and 2:00 positions [5, 17, 21, 23-25]; subcutaneous penile ring block ( $\mathrm{RB}$ ) which consists of the injection of
$0.8 \mathrm{ml}$ of $1 \%$ lidocaine in a circumferential ring around either the midshaft or at the level of the corona [5, 30, 32].

Other pharmacological interventions used were caudal block with bupivacaine [29], topical lidocaine cream (LMX4) containing 4\% lidocaine [23], and acetaminophen/ tylenol administered at the dosage of $10 \mathrm{mg} / \mathrm{kg}$ [18, 20, 24]. Among the non-pharmacological measures for pain control, the most commonly used were breast milk ad libitum during the procedure [28], sucrose solution (24-25\% sucrose) [22, 30-32], dextrose solution (50\% dextrose) [17], non-nutritive sucking (NNS) provided in the form of a gloved finger [24], and audio-stimulation with music (lullabies or repetitive rhythms) [19].

The ways used to assess pain response in neonates were both specific pain scales and physiological and behavioral responses to pain. NIPS (Neonatal Infant Pain Scale) was the most commonly used. Other methods to establish pain level were PIPP (premature infant pain profile), FLACC (Face, Legs, Activity, Cry, Consolability scale), NFCS (Neonatal Facial Coding System), N-PASS (Neonatal Pain, Agitation, and Sedation Scale), MBPS (Modified Behavioral 
Table 2 Comparison of analgesic methods for male circumcision

\begin{tabular}{|c|c|c|c|c|}
\hline Authors & Sample size $(n)$ & Pain scale & Technique & Results \\
\hline Kass et al. [17] & 47 & $\begin{array}{l}\text { crying time/MBPS/heart } \\
\text { rate/respiratory rate }\end{array}$ & Gomco & $D P N B(n=24)$ vs. dextrose solution $(n=23)$ \\
\hline Macke et al. [18] & 60 & NCAFS/crying time/heart rate & Gomco & Acetaminophen vs. placebo \\
\hline Malnory et al. [20] & 53 & NIPS & Gomco & Acetaminophen vs. placebo \\
\hline Choi et al. [21] & 63 & NIPS & unknown & $\begin{array}{l}\text { EMLA and sodium chloride solution DPNB } \\
(n=31) \text { vs. placebo cream and bupivacaine } \\
\text { DPNB }(n=32)\end{array}$ \\
\hline Lehr et al. [23] & 53 & heart rate/respiratory rate/SpO2 & Gomco & DPNB vs. EMLA vs. Lidocaine $4 \%$ cream \\
\hline South et al. [24] & 44 & $\mathrm{PIPP} /$ heart rate/crying time & Gomco & $\begin{array}{l}\text { DPNB + Tylenol }(n=22) \text { vs. DPNB }+ \text { Tylenol } \\
\quad+\text { non-nutritive sucking }(n=22)\end{array}$ \\
\hline Lehr et al. [27] & 53 & NFCS/crying time & Gomco & DPNB vs. EMLA vs. Lidocaine $4 \%$ cream \\
\hline Banieghbal et al. [28] & 581 & NIPS & Gomco & RB vs. $R B+$ milk/sucrose \\
\hline Bilgen et al. [29] & 50 & NIPS & Unknown & $\begin{array}{l}\text { Caudal block with low volume high concentration } \\
\text { bupivacaine vs. Caudal block with standard } \\
\text { dose bupivacaine }\end{array}$ \\
\hline Roman-Rodriguezet al. [30] & 791 & NIPS & Gomco & sucrose vs. $R B+$ sucrose \\
\hline Al Qahtani et al. [31] & 90 & N-PASS & Plastibell & EMLA vs. sucrose vs. EMLA + sucrose \\
\hline Sharara-Chami et al. [32] & 70 & NIPS & Gomco & $\begin{array}{l}\text { EMLA vs. EMLA + sucrose vs. EMLA + sucrose } \\
+ \text { DPNB vs. EMLA + sucrose }+R B\end{array}$ \\
\hline Modekwe et al. [33] & 110 & $\mathrm{SpO} 2$ & Plastibell & EMLA vs. $D P N B$ \\
\hline
\end{tabular}

In italics are the most effective analgesic methods and the studies using validated pain scales

Pain Scale), crying time, and the assessment of vital signs such as heart rate, oxygen saturation, and respiratory rate changes.

Ten articles, with more than 20 patients enrolled for each group, recorded pain levels during $\mathrm{MC}$ using validated pain scales [18, 20, 21, 24, 27-32].

\section{Dorsal penile nerve block}

Ten papers compared DPNB with other anesthetic techniques [17, 21-27, 32, 33].

In two papers, DPNB was performed using bupivacaine $[21,25]$; in one, DPNB with bupivacaine was proven more effective than DPNB with lidocaine [25]. DPNB with lidocaine was used for all the other studies [17, 22-24, 26, 27, $32,33]$. In 6 studies, DPNB was found to be more effective than the alternative measures used [17, 21, 22, 26, 32, 33]. In 4 studies, DPNB was combined with other forms of analgesia such as sucrose, EMLA, tylenol, and non-nutritive sucking. In all, the combined use of DPNB and additional pain-relieving methods proved to be effective [22, 24, 25, 32].

\section{EMLA}

Nine studies focused on the effects of EMLA topical cream in producing analgesia during $\mathrm{MC}$ comparing it with other methods [19, 21-23, 26, 27, 31-33]. One study showed higher pain scores when EMLA cream was used as a sole analgesic method [32], and in the papers by Garry et al. and by Modekewe et al., EMLA was proven inferior to DPNB [26, 33]. Two studies demonstrated that the effectiveness of EMLA was higher when combined with other analgesic strategies, either pharmacological or non-pharmacological [31, 32]. Three studies found no significant differences in the comparison of EMLA with other analgesic strategies, namely
Table 3 Comparison of surgical techniques for male circumcision

\begin{tabular}{lcll}
\hline Authors & Sample size & Technique & Analgesia \\
\hline Taddio et al. [36] & 86 & Mogen vs. Gomco & $\begin{array}{c}\text { DPNB + EMLA + acetaminophen } \\
\text { (Mogen)/EMLA (Gomco) }\end{array}$ \\
Kaufman et al. [37] & 57 & Mogen vs. Gomco & $\begin{array}{c}\text { EMLA + sucrose /EMLA + water } \\
\text { DPNB + sucrose }\end{array}$ \\
Taeusch et al. [38] & 59 & Mogen vs. Plastibell & $\begin{array}{l}\text { DPNB + sucrose } \\
\text { RB + sucrose }\end{array}$ \\
Sinkey et al. [39] & 274 & Mogen vs. Gomco & .
\end{tabular}


DPNB and lidocaine cream [21, 23, 27]. In one study, EMLA proved to be more effective when combined with music [19]. An older study by Russell et al., in which MC was performer with Plastibell technique, reported a complete alleviation of pain with the application of EMLA $1 \mathrm{~h}$ prior to the procedure [34]. Another study by Taddio et al. in 1997 recorded behavioral (facial activity and time spent crying) and physiologic (heart rate and blood pressure) responses during MC performed with Gomco clamp, and demonstrated that EMLA is efficacious and safe for the prevention of pain from circumcision in neonates [35].

\section{Ring block}

Four papers analyzed the effectiveness of ring block anesthesia either alone or combined with other strategies [22, 28, 30, $32]$. RB combined with oral sucrose was found to be more effective than RB alone [22, 30]. In one study, RB combined with EMLA and sucrose was significantly more effective than both EMLA + sucrose and DPNB + EMLA + sucrose [32]. In one study, RB along with breast milk and/or $20 \%$ sucrose resulted in painless circumcision for neonates under 2 weeks old, with a NIPS score of 0 to 2 [28].

\section{Caudal block}

One study assessed the effectiveness of caudal block performed either with low-volume high-concentration bupivacaine $(0.375 \%)$ or standard dose of bupivacaine $(0.25 \%)$. Block onset time and NIPS score were identical between the two groups demonstrating the effectiveness of highconcentration bupivacaine [29].

\section{Acetaminophen}

Two studies compared the use of acetaminophen vs. placebo to obtain analgesia during MC $[18,20]$. One study found no difference between the two groups [18]; by contrast, the paper by Malnory et al. showed a stronger analgesia in newborns receiving acetaminophen [20].

\section{Lidocaine cream}

Two papers evaluated the use of lidocaine $4 \%$ cream comparing it with lidocaine $2.5 \%$ cream, EMLA, and DPNB. Pain response was evaluated using the changes in vital signs and no significant modifications in heart rate were found with different analgesic methods. Mean respiratory rate during the procedure was lower with lidocaine $4 \%$ cream and with DPNB compared with EMLA [23, 27].

\section{Sucrose}

Results from multiple studies discourage the use of sucrose alone due to the lack of its analgesic effect [17, 22, 30, 31].

\section{MC surgical techniques}

Thirteen out of 17 studies disclosed which surgical techniques were used for MC, Gomco being the most commonly utilized. Four papers compared the differences in pain profile with the use of different surgical techniques [36-39]. All studies demonstrated that MC performed with Mogen clamp was faster. Three papers compared Mogen clamp with Gomco clamp, demonstrating that Mogen clamp causes less pain especially when combined with preoperative analgesia (either with DPNB plus EMLA and acetaminophen, RB plus sucrose, or EMLA plus sucrose) [36, 37, 39]. Another study compared Mogen clamp with Plastibell procedure, using DPNB + dextrose as analgesia, finding no significant differences in terms of crying time [38].

\section{Discussion}

It was once thought that newborns were unable to feel pain and that painful sensations experienced during the neonatal period would have easily been forgotten by them. It is now known, however, that newborns do feel pain and there is evidence that this can have physiological and behavioral consequences. Newborns are strongly susceptible to painful stimuli because, while ascending neural pathways for nociception are well-developed by the second trimester of pregnancy, the modulatory descending pathways are immature, even in term newborns [40-42]. There is ongoing research regarding the effects of prolonged or repetitive painful stimuli on newborns' neurodevelopment, provoking a decreased brain growth in the frontal and parietal lobes and alterations in organization of neuronal connections in the temporal lobes [9, 43, 44]. Taddio et al. demonstrated a stronger pain response to routine vaccination in infants circumcised without anesthesia in comparison with uncircumcised infants or circumcised babies treated with topical anesthesia; they argued that MC without anesthetic may induce changes in infant pain behavior because of alterations in the neural processing of painful stimuli [10]. By contrast, a recent analysis by O'Callahan et al. demonstrated that newborns circumcised with proper analgesia (24\%sucrose plus local anesthesia with lidocaine or DPNB and acetaminophen) showed no differences in the rate of exclusive breastfeeding during the initial hospitalization compared with non-circumcised newborns [45]. Therefore, it is imperative for clinicians to attempt all the possible strategies to reduce neonatal pain, and since MC is an invasive painful 
procedure, performing it without anesthesia appears to be contraindicated [8].

The studies we retrieved displayed heterogeneity in terms of sample size, pain scales, analgesic methods, and surgical techniques used. In some studies, the surgical details were not specified, and others used non-specific methods for pain evaluation (e.g., crying time, heart rate, respiratory rate). As a consequence and limitation of the study, it was not possible to perform a metaanalysis of different studies. Analyzing the studies with more than 20 patients for each study group and that used a validated pain scale, it was clear that the best results were obtained with pharmacologic local anesthesia and in particular the combination of pharmacological and non-pharmacological methods [20, 21, 24, 27-32]. As demonstrated by South et al., adding nonnutritive sucking to a combination of DPNB and tylenol resulted in lower pain scores compared with the use of pharmacological methods alone [24].

The value of combining non-pharmacological analgesic methods with DPNB has been demonstrated not only in newborns but also in older infants [12]. Similarly, by adding sucrose to other analgesic methods, either EMLA, DPRB, or $\mathrm{RB}$, the result was a minimal pain level during MC [30-32]. These findings are in accordance with the work by Stevens at al. demonstrating the value of sucrose administration during painful procedures in neonates [46].

Only one study compared DPNB with RB, both associated with EMLA and sucrose, demonstrating a better analgesic effect when the combination of RB + EMLA + sucrose was used [32]. This finding confirmed the results of an older study by Lander et al. showing that RB is superior to DPNB [47].

Regarding surgical techniques, the general belief is that Mogen technique is shorter in terms of duration compared with Gomco or Plastibell [36-39]. A large study by Sinkey et al. suggests that Mogen technique is also less painful than Gomco [39]. However, in the majority of trials comparing analgesic methods that were considered in this review, MC was performed using Gomco. One reason for this might be the fact that the choice of the surgical technique is variable between centers, and there seems to be a trend toward the use of Gomco in Western countries' in-hospital settings [48, 49].

Two studies focused mainly on post-operative analgesia showing lower pain levels and longer-lasting analgesia with the use of bupivacaine as an anesthetic agent during MC [25, 29].

Despite the great variability that undoubtedly exists regarding the provision of analgesia during $\mathrm{MC}$, the use of a combined pharmacological and non-pharmacological approach could be considered safe and effective. As we stated in our previous work on this topic, we are convinced that a possible valuable adjunct to the current perspective might be the integration of sensorial saturation (SS) as an aid to pharmacological analgesia for MC [50]. SS is a validated method to reduce newborns' stress response to nociception and is based on the so-called gate-control theory by which the brainstem can filter and reduce the transmission of pain to the brain if the person is concentrated on something else. In this way, by attracting babies' attention with positive stimuli (tactile, auditory, gustatory, and visual), it is possible to reduce and even nullify the perception of painful stimuli [51].

In conclusion, since a standardized protocol for analgesia during $\mathrm{MC}$ is yet to be determined, we encourage more research in this field as a possible implementation of current clinical practice, in order to ameliorate the current strategies so that newborns' MC might eventually become a painless procedure. Given the proven effects of SS, a possible strategic direction to pursue in the field of MC analgesia could be the combination of pharmacological methods with SS, possibly potentiating the already proven positive effects of sucrose in conjunction with anesthetic drugs.

Authors' contributions S. Rossi: conceptualization and study design, results analysis, writing of the manuscript.

G. Buonocore: general supervision and revision.

C. V. Bellieni: conceptualization, study design and methodology definition, supervision, revision of the manuscript.

Funding Information Open access funding provided by Università degli Studi di Siena within the CRUI-CARE Agreement.

\section{Compliance with ethical standards}

Conflict of interest The authors declare that they have no conflict of interest.

Ethical approval This article does not contain any studies with human participants or animals performed by any of the authors.

Open Access This article is licensed under a Creative Commons Attribution 4.0 International License, which permits use, sharing, adaptation, distribution and reproduction in any medium or format, as long as you give appropriate credit to the original author(s) and the source, provide a link to the Creative Commons licence, and indicate if changes were made. The images or other third party material in this article are included in the article's Creative Commons licence, unless indicated otherwise in a credit line to the material. If material is not included in the article's Creative Commons licence and your intended use is not permitted by statutory regulation or exceeds the permitted use, you will need to obtain permission directly from the copyright holder. To view a copy of this licence, visit http://creativecommons.org/licenses/by/4.0/.

\section{References}

1. Morris BJ, Wamai RG, Henebeng EB, Tobian AA, Klausner JD, Banerjee J, Hankins CA (2016) Estimation of country-specific and global prevalence of male circumcision. Popul Health Metrics 14:4. Erratum in: Popul Health Metr. 2016;14:11. https://doi.org/10. 1186/s12963-016-0073-5

2. Introcaso CE, Xu F, Kilmarx PH, Zaidi A, Markowitz LE (2013) Prevalence of circumcision among men and boys aged 14 to 59 years in the United States, National Health and Nutrition 
Examination Surveys 2005-2010. Sex Transm Dis 40(7):521-525. https://doi.org/10.1097/01.OLQ.0000430797.56499.0d

3. Joint United Nations Programme on HIV/AIDS (UNAIDS). Neonatal and child male circumcision: a global review. April, 2010. Available at: https://www.who.int/hiv/pub/ malecircumcision/neonatal_child_MC_UNAIDS.pdf

4. Many BT, Rizeq YK, Vacek J, Cheon EC, Johnson E, Hu YY, Raval MV, Abdullah F, Goldstein SD (2020) A contemporary snapshot of circumcision in US children's hospitals. J Pediatr Surg 55(6):1134-1138. https://doi.org/10.1016/j.jpedsurg.2020. 02.031

5. Blank S, Brady M, Buerk E, Carlo W, Diekema D, Freedman A, Maxwell L, Wegner S (2012) Male circumcision. Pediatrics 130(3): e756. https://doi.org/10.1542/peds.2012-1990

6. Simpson E, Carstensen J, Murphy P (2014) Neonatal circumcision: new recommendations \& implications for practice. Mo Med 111(3):222-230

7. Morris BJ, Kennedy SE, Wodak AD, Mindel A, Golovsky D, Schrieber L, Lumbers ER, Handelsman DJ, Ziegler JB (2017) Early infant male circumcision: systematic review, risk-benefit analysis, and progress in policy. World J Clin Pediatr 6(1):89102. https://doi.org/10.5409/wjcp.v6.i1.89

8. Paix BR, Peterson S (2012) Circumcision of neonates and children without appropriate anaesthesia is unacceptable practice - reply. Anaesth Intensive Care 40(4):721-722. https://doi.org/10.1177/ 0310057X1204000318

9. Walker SM (2019) Long-term effects of neonatal pain. Semin Fetal Neonatal Med 24(4):101005. https://doi.org/10.1016/j.siny.2019. 04.005

10. Taddio A, Katz J, Ilersich AL, Koren G (1997) Effect of neonatal circumcision on pain response during subsequent routine vaccination. Lancet 349(9052):599-603. https://doi.org/10.1016/S01406736(96)10316-0

11. McPherson C, Inder T (2017) Perinatal and neonatal use of sedation and analgesia. Semin Fetal Neonatal Med 22(5):314-320. https:// doi.org/10.1016/j.siny.2017.07.007

12. Nguyen TT, Kraft E, Nasrawi Z, Joshi M, Merianos D (2019) Avoidance of general anesthesia for circumcision in infants under 6 months of age using a modified Plastibell technique. Pediatr Surg Int 35(5):619-623. https://doi.org/10.1007/s00383-019-04452-x

13. Brady-Fryer B, Wiebe N, Lander JA (2004) Pain relief for neonatal circumcision. Cochrane Database Syst Rev (3) Art. No.: CD004217. https://doi.org/10.1002/14651858.CD004217.pub2

14. Sandeman DJ, Dilley AV (2007) Ultrasound guided dorsal penile nerve block in children. Anaesth Intensive Care 35:266-269. https://doi.org/10.1177/0310057X0703500217

15. Sandeman DJ, Reiner D, Dilley AV, Bennett MH, Kelly KJ (2010) A retrospective audit of three different regional anaesthetic techniques for circumcision in children. Anaesth Intensive Care 38: 519-524. https://doi.org/10.1177/0310057X1003800317

16. Moher D, Liberati A, Tetzlaff J, Altman DG, The PRISMA Group (2009) Preferred reporting items for systematic reviews and metaanalyses: the PRISMA statement. PLoS Med 6(7):e1000097

17. Kass FC, Holman JR (2001) Oral glucose solution for analgesia in infant circumcision. J Fam Pract 50(9):785-788

18. Macke JK (2001) Analgesia for circumcision: effects on newborn behavior and mother/infant interaction. J Obstet Gynecol Neonatal Nurs 30(5):507-514. https://doi.org/10.1111/j.1552-6909.2001. tb01570.x

19. Joyce BA, Keck JF, Gerkensmeyer J (2001) Evaluation of pain management interventions for neonatal circumcision pain. $\mathrm{J}$ Pediatr Health Care 15(3):105-114. https://doi.org/10.1067/mph. 2001.110272

20. Malnory M, Johnson TS, Kirby RS (2003) Newborn behavioral and physiological responses to circumcision. MCN Am J Matern Child
Nurs 28(5):313-317; quiz 318-9. https://doi.org/10.1097/ 00005721-200309000-00009

21. Choi WY, Irwin MG, Hui TWC, Lim HH, Chan KL (2003) EMLA cream versus dorsal penile nerve block for postcircumcision analgesia in children. Anesth Analg 96(2):396-399. https://doi.org/10. 1097/00000539-200302000-00018

22. Razmus S, Dalton ME, Wilson D (2004) Pain management for newborn circumcision. Pediatr Nurs 30(5):414-417 427

23. Lehr VT, Cepeda E, Frattarelli DAC, Thomas R, LaMothe J, Aranda JV (2005) Lidocaine 4\% cream compared with lidocaine $2.5 \%$ and prilocaine $2.5 \%$ or dorsal penile block for circumcision. Am J Perinatol 22(5):231-237. https://doi.org/10.1055/s-2005871655

24. South MMT, Strauss RA, South AP, Boggess JF, Thorp JM (2005) The use of non- nutritive sucking to decrease the physiologic pain response during neonatal circumcision: a randomized controlled trial. Am J Obst Gynecol 193(2):537-543. https://doi.org/10. 1016/j.ajog.2005.03.060

25. Stolik-Dollberg OC, Dollberg S (2005) Bupivacaine versus lidocaine analgesia for neonatal circumcision. BMC Pediatr 5:3-6. https://doi.org/10.1186/1471-2431-5-12

26. Garry DJ, Swoboda E, Elimian A, Figueroa R (2006) A video study of pain relief during newborn male circumcision. J Perinatol 26(2): 106-110. https://doi.org/10.1038/sj.jp.7211413

27. Lehr VT, Zeskind PS, Ofenstein JP, Cepeda E, Warrier I, Aranda JV (2007) Neonatal facial coding system scores and spectral characteristics of infant crying during newborn circumcision. Clin J Pain 23(5):417424. https://doi.org/10.1097/AJP.0b013e31805476f2

28. Banieghbal B (2009) Optimal time for neonatal circumcision: an observation-based study. Pediatr Urol 5(5):359-362. https://doi. org/10.1016/j.jpurol.2009.01.002

29. Bilgen S, Koner O, Menda F, Karacay S, Kaspar EC, Sozubir S (2013) A comparison of two different doses of bupivacaine in caudal anesthesia for neonatal circumcision. A randomized clinical trial. Middle East J Anaesthesiol 22(1):93-98

30. Roman-Rodriguez CF, Toussaint T, Sherlock DJ, Fogel J, Hsu CD (2014) Pre-emptive penile ring block with sucrose analgesia reduces pain response to neonatal circumcision. Urology 83(4): 893-898. https://doi.org/10.1016/j.urology.2013.10.010

31. Al Qahtani R, Abu-Salem L, Pal K (2014) Effect of lidocaineprilocaine eutectic mixture of local anaesthetic cream compared with oral sucrose or both in alleviating pain in neonatal circumcision procedure. Afr J Paediatr Surg 11(1):56-61. https://doi.org/10. 4103/0189-6725.129236

32. Sharara-Chami R, Lakissian Z, Charafeddine L, Milad N, El-Hout $\mathrm{Y}$ (2017) Combination analgesia for neonatal circumcision: a randomized controlled trial. Pediatrics 140(6):e20171935. https://doi. org/10.1542/peds.2017-1935

33. Modekwe VI, Ugwu JO, Ekwunife OH, Osuigwe AN, Obiechina SO, Okpalike IV, Orakwe JC (2019) Comparison of the efficacy of eutectic mixture of local anesthetics (EMLA) and dorsal penile nerve block (DPNB) in neonatal circumcision. Niger J Clin Pract 22(12):1737-1741. https://doi.org/10.4103/njcp.njcp_266_19

34. Russell CT, Chaseling J (1996) Topical anaesthesia in neonatal circumcision: a study of 208 consecutive cases. Aust Fam Phys Suppl 1:S30-S34

35. Taddio A, Stevens B, Craig K, Rastogi P, Ben-David S, Shennan A Mulligan P, Koren G (1997) Efficacy and safety of lidocaineprilocaine cream for pain during circumcision. N Engl J Med 336(17):1197-1201. https://doi.org/10.1056/NEJM199704243361701

36. Taddio A, Pollock N, Gilbert-MacLeod C, Ohlsson K, Koren G (2000) Combined analgesia and local anesthesia to minimize pain during circumcision. Arch Pediatr Adolesc Med 154(6):620-623. https://doi.org/10.1001/archpedi.154.6.620

37. Kaufman GE, Cimo S, Miller LW, Blass EM (2002) An evaluation of the effects of sucrose on neonatal pain with 2 commonly used 
circumcision methods. Am J Obstet Gynecol 186(3):564-568. https://doi.org/10.1067/mob.2002.121621

38. Taeusch HW, Martinez AM, Partridge JC, Sniderman S, Armstrong-Wells J, Fuentes-Afflick E (2002) Pain during Mogen or PlastiBell circumcision. J Perinatol 22(3):214-221. https://doi. org/10.1038/sj.jp.7210653

39. Sinkey RG, Eschenbacher MA, Walsh PM, Doerger RG, Lambers DS, Sibai BM, Habli MA (2015) The GoMo study: a randomized clinical trial assessing neonatal pain with Gomco vs Mogen clamp circumcision. Am J Obstet Gynecol 212(5):664.e1-664.e8. https:// doi.org/10.1016/j.ajog.2015.03.029

40. Fitzgerald $\mathrm{M}(2015)$ What do we really know about newborn infant pain? Exp Physiol 100(12):1451-1457. https://doi.org/10.1113/ EP085134

41. Fitzgerald M (2000) Development of pain pathways and mechanisms. In: McGrath PJ, Anand JKS, Stevens BJ (eds) Pain in neonates, 2nd edn. Elsevier, pp 9-21

42. Lago P, Ancora G, Bellieni CV, Cavazza A, Cocchi G, Guadagni AM, Memo L, Merazzi D, Pirelli A (2006) Linee-guida e raccomandazioni per la prevenzione ed il trattamento del dolore nel neonato. Pediatr Med Chir 28(1-3):24-34

43. Walker SM (2014) Neonatal pain. Paediatr Anaesth 24(1):39-48. https://doi.org/10.1111/pan.12293

44. McPherson C, Grunau RE (2014) Neonatal pain control and neurologic effects of anesthetics and sedatives in preterm infants. Clin Perinatol 41(1):209-227. https://doi.org/10.1016/j.clp.2013.10.002

45. O'Callahan C, Te S, Husain A, Rosener SE, Hussain N (2020) The effect of circumcision on exclusive breastfeeding, phototherapy, and hospital length of stay in term breastfed newborns. Hosp Pediatr 10(6):516-522. https://doi.org/10.1542/hpeds.2019-0270

46. Stevens B, Yamada J, Ohlsson A, Haliburton S, Shorkey A (2016) Sucrose for analgesia in newborn infants undergoing painful procedures. Cochrane Database Syst Rev 7(7). https://doi.org/10.1002/ 14651858.CD001069.pub5

47. Lander J, Brady-Fryer B, Metcalfe JB, Nazarali S, Muttitt S (1997) Comparison of ring block, dorsal penile nerve block, and topical anesthesia for neonatal circumcision: a randomized controlled trial. JAMA. 278(24):2157-2162

48. Chan PS, Penna FJ, Holmes AV (2018) Gomco versus Mogen? No effect on circumcision revision rates. Hosp Pediatr 8(10):611-614. https://doi.org/10.1542/hpeds.2018-0263

49. Heras A, Vallejo V, Pineda MI, Jacobs AJ, Cohen L (2018) Immediate complications of elective newborn circumcision. Hosp Pediatr 8(10):615-619. https://doi.org/10.1542/hpeds.2018-0005

50. Bellieni CV, Alagna MG, Buonocore G (2013) Analgesia for infants' circumcision. Ital J Pediatr 39(1):1-3213. https://doi.org/10. 1080/14767058.2017.1366983

51. Locatelli C, Bellieni CV (2018) Sensorial saturation and neonatal pain: a review. J Mater Fetal Neonatal Med 31(23):3209-3213. https://doi.org/10.1080/14767058.2017.1366983

Publisher's note Springer Nature remains neutral with regard to jurisdictional claims in published maps and institutional affiliations. 